\title{
Estratégias fenológicas de Senna cana (Nees \& Mart.) H.S. Irwin \& Barneby (Fabaceae: Caesalpinioideae) como mecanismo eficiente para atração de polinizadores
}

Isys Mascarenhas Souza ${ }^{1,2}$, Karoline Coutinho ${ }^{1}$ e Ligia Silveira Funch ${ }^{1}$

\begin{abstract}
RESUMO
(Estratégias fenológicas de Senna cana (Nees \& Mart.) H.S. Irwin \& Barneby (Fabaceae: Caesalpinioideae) como mecanismo eficiente para atração de polinizadores). Este trabalho verificou a importância das estratégias fenológicas de Senna cana na atração de visitantes e polinizadores na mata ciliar do rio Lençóis, Chapada Diamantina, Bahia. As observações fenológicas foliares (queda foliar e brotamento) e reprodutivas (botão, flor, fruto imaturo e fruto maduro) foram mensais (18 meses) em 10 indivíduos marcados. Para a biologia floral observou-se: antese, duração das flores, receptividade estigmática, viabilidade polínica, presença de osmóforos e pigmentos que refletem raios ultravioleta. Foram realizados testes de autopolinização manual, espontânea e polinização cruzada. Os visitantes e polinizadores foram determinados observando-se: horário, duração, freqüência das visitas e comportamento de forrageio. Senna cana é uma espécie perenifólia episódica, com eventos reprodutivos sazonais e altamente sincrônicos (floração intermediária no período chuvoso e frutificação longa no período seco). Tais características na floração, somadas à síndrome de melitofilia, configuram importantes estratégias para atração de visitantes florais, dentre os quais Xylocopa frontalis e $X$. grisescens foram classificadas enquanto potenciais polinizadores. A autoincompatibilidade e o máximo de frutos produzidos após polinização cruzada são mecanismos reprodutivos favorecidos pelas estratégias fenológicas e síndrome de polinização apresentadas pela espécie.
\end{abstract}

Palavras-chave: Fabaceae, Melitofilia, Sazonalidade e Sincronia

\begin{abstract}
(Phenological strategies of Senna cana (Nees \& Mart.) H.S. Irwin \& Barneby (Fabaceae: Caesalpinioideae) as efficient mechanisms for attracting pollinators). The present work evaluated the importance of the phenological strategies of Senna cana in attracting floral visitors and pollinators in an riparian forest along the Lençóis River, in Chapada Diamantina, Bahia, Brazil. Vegetative and reproductive phenological observations (leaf fall, leaf flushing, flowering, and fruiting) were made on a monthly basis among a group of 10 individuals. The floral biology patterns observed included: anthesis, duration of the flowers, stigma receptivity, pollen viability, and the presence of osmophores and pigments that reflect UV light. Reproductive mechanisms were examined by testing manual and natural self-pollination as well as cross-pollination. Visitors and pollinators were identified, and the time, duration, and frequency of their visitation, as well as their behavior, were noted. Senna cana is an episodic evergreen species showing seasonal and highly synchronous reproductive events (intermediate flowering after a rainy period, and long fruiting during the dry period). These flowering characteristics, in addition to the syndrome of melittophily, are important strategies for attracting floral visitors (including Xylocopa frontalis and X. grisescens, which are potential pollinators). The selfincompatibility and maximization of fruit production through cross-pollination represent reproductive mechanisms favored by the phenological strategies and the pollination syndrome demonstrated by this species.
\end{abstract}

Key words: Fabaceae, Melittophily, Seasonality, Synchrony

\footnotetext{
1 Universidade Estadual de Feira de Santana, Departamento de Ciências Biológicas, Feira de Santana, BA, Brasil

2 Autor para correspondência: isys.souza@gmail.com
} 


\section{Introdução}

Senna (K.Bahuin) Miller é um gênero Pantropical de Fabaceae, com cerca de 200 espécies nas Américas (Queiroz 2009 apud Lewis 2005b), onde muitas delas apresentam caráter ornamental e medicinal. Dentre elas, Senna cana (Nees \& Mart.) H.S. Irwin \& Barneby, conhecida popularmente como são joão, ocorre principalmente em cerrados e campos rupestres, e caracteriza-se por apresentar flores amarelas, vistosas, sem nectários, e anteras amarelas, rígidas, poricidas (Queiroz 2009).

A fenologia reprodutiva das plantas afeta não somente as próprias espécies como também os animais que dependem de seus recursos. Assim, estudos abordando características fenológicas e as interações das plantas com seus polinizadores podem demonstrar como fatores ecológicos e evolutivos tem influenciado a organização temporal da floração (Newstrom et al. 1994).

Nesse sentido, diversos estudos fenológicos (Bulhão \& Figueiredo 2002; Martin-Gajardo \& Morellato 2003; Lenzi \& Orth 2004; Locatelli \& Machado 2004; Santos \& Takaki 2005; Cerqueira et al. 2008; Marques \& Lemos Filho 2008), e envolvendo a biologia floral, visitantes e polinizadores (Dutra \& Machado 2001; Machado \& Lopes 2004; Lenzi et al. 2005; Gimenes \& Lobão 2006; Vásquez \& Webber 2010) têm sido realizados em diferentes grupos de plantas.

Em Senna, tais estudos ainda são relativamente escassos (Silva et al. 2002; Carvalho \& Oliveira 2003; Oberlaender 2006; Pinheiro \& Sazima 2007; Torres 2009), mas sugerem um padrão dentro do grupo no que diz respeito ao sistema reprodutivo, estratégias fenológicas e polinização observadas nas espécies. Assim, este trabalho descreveu a fenologia, a biologia floral e os visitantes florais de Senna cana (Nees \& Mart.) H.S. Irwin \& Barneby presentes na mata ciliar do rio Lençóis, Chapada Diamantina, Bahia, a fim de auxiliar na compreensão da relação entre as estratégias fenológicas e os mecanismos utilizados para a atração de visitantes florais em Senna.

\section{Material e métodos}

O estudo foi desenvolvido na mata ciliar do rio Lençóis, município de Lençóis, Chapada Diamantina, Bahia ( $41^{\circ} 24^{\prime} 5,2^{\prime \prime} \mathrm{W}$ e $\left.12^{\circ} 33^{\prime} 40,0^{\prime \prime} \mathrm{S}\right)$, a $500 \mathrm{~m}$ de altitude. A região apresenta clima mesotérmico, tropical semiúmido, com predomínio das chuvas no verão e período seco bem demarcado no inverno (Funch et al. 2002), padrão verificado na média histórica de precipitação e temperatura para a região (1976 a 2008) (Fig. 1A). Segundo dados fornecidos pelo Instituto Nacional de Meteorologia (INMET), a região apresentou uma precipitação atípica durante o período de estudo, com 306,1 mm em outubro/2009, quando seria o período seco, e apenas $81,5 \mathrm{~mm}$ em dezembro/2009, quando seria o período chuvoso (Fig.1B), diferindo do padrão observado na Fig. 1A. A temperatura média mensal manteve- -se dentro da variação histórica prevista para a região (22 a $25^{\circ} \mathrm{C}$ ) (Fig. 1B). E de acordo com as médias de fotoperíodo (Lammi 2005), a região apresentou dias mais longos entre novembro e janeiro (verão), e dias mais curtos entre maio e julho (inverno) (Fig. 1C).

As observações fenológicas foram realizadas mensalmente, entre maio/2009 e outubro/2010, em dez indivíduos marcados de Senna cana. As fenofases observadas foram: queda foliar, brotamento, botões florais, flores, frutos imaturos e frutos maduros, sendo sua intensidade estimada de acordo com Fournier (1974). Estratégias fenológicas foliares foram descritas segundo Frankie et al. (1974) e as reprodutivas de acordo com Newstrom et al. (1994). Analisou-se a relação das fenofases com as variáveis ambientais através da correlação de Spearman, de acordo com Siegel (1975), com nível de significância de 0,05. A sincronia intraespecífica foi verificada através do índice de atividade proposto por Bencke \& Morellato (2002).

Para a biologia floral, as observações em campo foram realizadas em dois períodos: (I) 15-17 de fevereiro e (II) 25-31 de março de 2010. O horário e duração da antese, bem como a duração das flores, foram acompanhados em um total de 15 botões florais em pré-antese em indivíduos diferentes. Os demais experimentos referentes à biologia floral seguiram metodologias propostas por Dafni (1992), sendo: receptividade estigmática observada em campo, com o auxílio de lupa de mão (10x), em um total de 30 botões em antese, 30 flores de $1^{\circ}$ dia e 30 flores de $2^{\circ}$ dia, em três medidas / dia (7:00, 12:00 e 17:00h); viabilidade polínica testada em laboratório, com auxílio de estereomicroscópio, a partir do preparo de lâminas dos grãos de pólen coletados de 15 botões em antese, 15 flores de $1^{\circ}$ dia e 15 flores de $2^{\circ}$ dia, em três medidas / dia (7:00, 12:00 e 17:00h); e a presença de osmóforos e pigmentos que refletem raios ultravioleta testadas em um total de 20 flores (10 / experimento), sendo o primeiro testado a partir da imersão das flores em solução de vermelho neutro $1 \%$, em um intervalo de tempo de 10 minutos, e o segundo através da submissão destas em atmosfera de hidróxido de amônio 5\%, durante 5 minutos.

Para análise do sistema reprodutivo: 10 botões em pré-floração foram previamente ensacados e após a sua antese foram realizados testes de autopolinização induzida. Para verificar a formação de frutos por meio de autopolinização espontânea, foram ensacados 30 botões. O teste de polinização cruzada manual foi realizado em 20 flores de $1^{\circ}$ dia as quais foram ensacadas após os testes. Para observar a taxa de frutos produzidos naturalmente, foram marcados 40 botões como grupo controle.

Amostras da espécie estudada foram coletadas, devidamente identificadas por especialista na família, preparadas e inseridas na coleção do Herbário da Universidade Estadual de Feira de Santana (HUEFS).

Os visitantes florais e prováveis polinizadores foram identificados através de observações focais em campo em três períodos: (I) 15-17 de fevereiro; (II) 25-26 de fevereiro; 


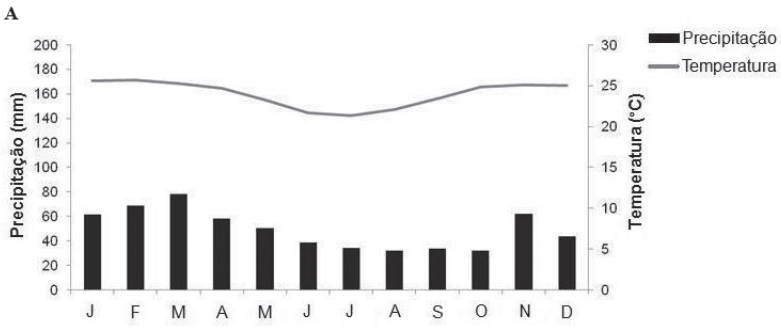

B
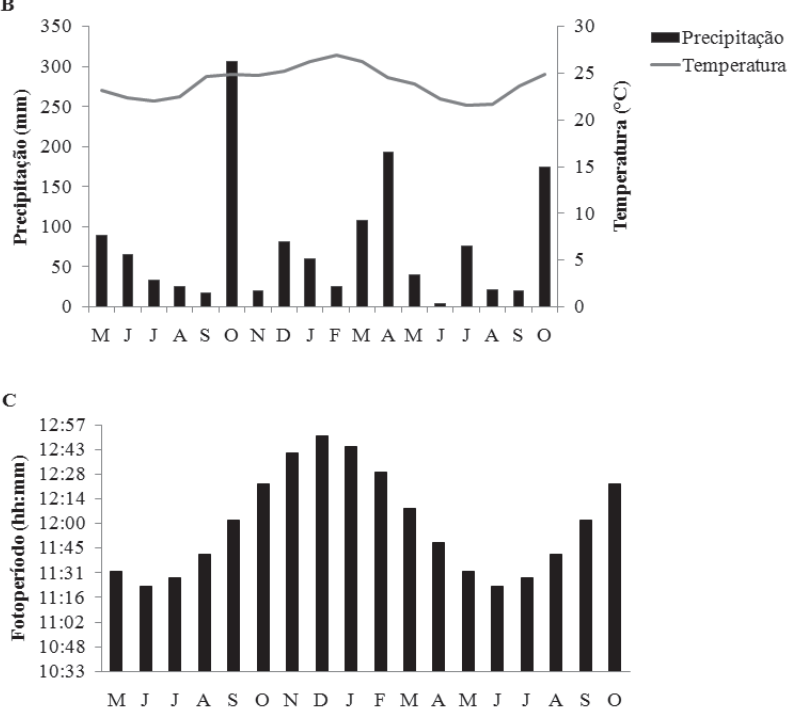

Figura 1. Variáveis ambientais na região de Lençóis, Chapada Diamantina, Bahia. A - Média histórica da precipitação e temperatura (1976 - 2008); B - Precipitação e temperatura média mensal (maio/2009 - outubro/2010); C - Médias de fotoperíodo (maio/2009 - outubro/2010).

(III) 30 de março de 2010, com 12 horas / dia de observação, a intervalos de 15 minutos a cada hora, totalizando 60 horas de observações para os dois primeiros períodos, e mais 6 horas no terceiro período (turno da manhã), verificando-se: horário, duração, freqüência e comportamento de forrageio do animal. Os visitantes foram classificados de acordo com as categorias estabelecidas por Inouye (1980).

Os insetos foram coletados com o auxílio de rede entomológica, sacrificados em câmara mortífera regada a éter e encaminhados ao laboratório, onde foram devidamente montados e depositados na Coleção Entomológica Johann Becker do Museu de Zoologia da Universidade Estadual de Feira de Santana (MZUEFS). As espécies de abelhas foram identificadas por especialista no grupo.

\section{Resultados e discussão}

\section{Fenologia}

Senna cana apresentou comportamento perenifólio episódico, com produção descontínua de muitas ou poucas folhas, mas sem concentração de queda foliar (Fig. 2A), não apresentando correlação significativa com quaisquer das variáveis ambientais analisadas. De acordo com o índice de atividade de queda foliar (Fig. 2B), verificou-se que a espécie exibiu alta sincronia na maioria dos meses, diferindo do brotamento que apresentou alta sincronia apenas nos meses de setembro e outubro (2009) e em janeiro e outubro do ano seguinte. Houve maior intensidade de produção foliar em outubro (2009 com 97,5\%), com sincronia plena e ausência de queda foliar, o que se repetiu com menor intensidade no ano seguinte (Fig. 2A).

A espécie estudada apresentou floração anual e intermediária, se estendendo de janeiro a abril, com máximo de botões e flores em março (22,5\% e 32,5\%, respectivamente) (Fig. 2C), antecedendo o pico de chuvas na região. Borges et al. (2002) observaram a mesma sazonalidade para $S$. gardneri (Benth.) H.S. Irwin \& Barneby e floração na estação seca em S. macranthera var. puibunda (Benth.) H.S. Irwin \& Barneby. Para duas outras espécies do gênero também foram descritos padrões anuais de floração: S. sylvestres (Vell.) H.S. Irwin \& Barneby (Carvalho \& Oliveira 2003) e S. australis (Vell.) H.S. Irwin \& Barneby (Silva et al. 2002), entretanto, somente a primeira se assemelhou a espécie estudada no que diz respeito a sazonalidade e duração do evento.

Segundo Bulhão \& Figueiredo (2002), em observações realizadas em dez espécies de Fabaceae presentes numa área de cerrado, o grupo tende a apresentar eventos vegetativos e reprodutivos sazonais, com brotamento coincidindo com a estação chuvosa, queda foliar com a estação seca e a floração, na maioria das espécies, também ocorrendo durante a estação seca e simultânea à renovação das folhas.

A fenofase frutificação de Senna cana foi anual e longa, com predomínio nos períodos secos, se estendendo de maio a setembro em 2009, e se repetindo em 2010 (abril a setembro), com máximas de frutos imaturos nos meses de maio e frutos maduros em julho e agosto (2009), e no ano seguinte, em junho e julho (Fig. 2C). A espécie apresentou sincronia alta à plena, para a fenofase em questão, coincidindo com certo aumento na queda foliar e redução da precipitação. Foi verificada correlação significativa negativa entre frutos imaturos e fotoperíodo $(\mathrm{p}<0,05 ; \mathrm{rs}=-0,75)$, e entre frutos maduros e temperatura $(\mathrm{p}<0,05$; rs $=-0,72)$, e fotoperíodo $(\mathrm{p}<0,05 ; \mathrm{rs}=-0,62)$. O desenvolvimento dos frutos coincidiu com os meses em que as médias de fotoperíodo diminuíram gradativamente, enquanto que a maturação e consequente dispersão das sementes ocorreram no período seco, com menores temperaturas médias mensais. As últimas sementes dispersas em setembro aguardam o início das chuvas na transição da estação seca-chuvosa (outubro-novembro).

Do mesmo modo como observado em S. cana, Oberlaender (2006) também descreveu para duas espécies de mata atlântica, Senna macranthera (DC. ex Collad.) H.S.Irwin \& Barneby e Senna multijuga (L.C.Richard) H.S.Irwin \& Barneby, uma queda foliar constante (com maior intensidade coincidindo em grande parte com o período de menor precipitação), floração episódica e frutificação longa. 

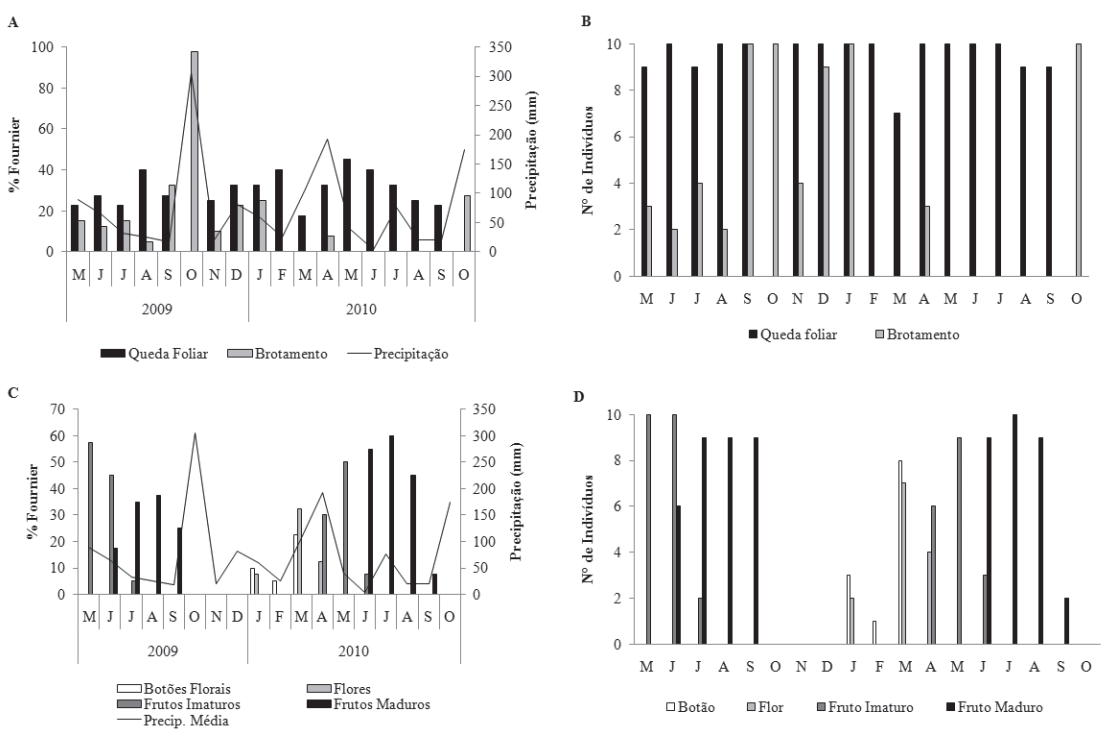

Figura 2. Intensidade das fenofases (A - Vegetativas; C - Reprodutivas) de Senna cana (Nees \& Mart.) H.S. Irwin \& Barneby, precipitação na região de Lençóis, Chapada Diamantina, Bahia (maio/2009 - outubro/2010), e sincronia intraespecífica (B - Vegetativas; D - Reprodutivas).

Foi notável a alta sincronia intraespecífica verificada nos períodos de maior atividade em todas as fenofases que resultou em relações bem evidentes entre as fases (Fig. 2B, 2D), por exemplo, entre as fases foliares quando os máximos de brotamento (outubro, com $100 \%$ de sincronia) foram marcados pela ausência de queda foliar (Fig. 2B). Entre a queda de folhas e o máximo de frutos maduros (junho a agosto), a alta sincronia nas fases foliar e reprodutiva favorece o processo de dispersão dos diásporos autocóricos que são liberados durante a estação seca com a copa menos cheia. Além disso, a alta sincronia dos indivíduos na floração de $S$. cana resulta numa eficiente estratégia para a atração de polinizadores (Augspurger 1981), o que somado ao espaçamento temporal do evento, reduz a competição por polinizadores com outras espécies vegetais que por ventura florescem no mesmo período e assim estariam competindo por polinizadores (Williams-Linera \& Meave 2002). Diante disso, percebe-se que os caracteres morfo-estruturais apresentados pelas flores não atuam isoladamente na atração dos polinizadores, tendo em vista que as estratégias fenológicas de floração desempenham um importante papel na atração destes (Castro 2001 apud Borges et al. 2002).

\section{Biologia Floral}

Senna cana é uma espécie arbustiva, com inflorescências racemosas, botões globosos, flores vistosas, zigomorfas, com sépalas amarelas, levemente esverdeadas, e pétalas amarelas, obovais; gineceu com pistilo esverdeado; enantiostilia; androceu composto por um conjunto de 10 estames (três estames maiores, basais; quatro pequenos, dispostos na porção mediana da flor; e três estaminódios na porção superior), anteras amarelas, rígidas, poricidas; e nectários florais ausentes. Diante dos caracteres morfológicos apresentados e do pólen, enquanto recurso floral oferecido, a espécie foi classificada como melitófila (Faegri \& van der Pijl 1979). Tais atributos garantem a atração de muitos visitantes florais, sobretudo, abelhas.

A espécie apresentou antese diurna e bastante lenta, iniciando por volta das 6:00h, sendo interrompida com o pôr do sol e reiniciando ao amanhecer. A maior parte dos botões acompanhados (40\%) levaram seis dias para completar o processo de abertura total da flor. Contudo, foi registrado que $20 \%$ dos botões levaram $4-7$ dias para completar a antese. Outros trabalhos também fizeram referência a antese diurna (por volta das 7:00 h) das flores de Senna: $S$. sylvestris (Carvalho \& Oliveira 2003) e S. multijuga (Torres 2009). Entretanto, Silva et al. (2002) verificaram em $S$. australis (Vell.) Irwin \& Barneby a antese iniciando em dois momentos: a noite (em torno de 20:00h) e pela manhã (por volta das 5:30h).

Em geral, as flores de S. cana apresentaram duração de três dias, permanecendo abertas até a sua senescência, de modo que: no $1^{\circ} \mathrm{dia}$, apresentaram-se vistosas, com pistilo esverdeado direcionando-se em algumas flores para a direita e outras para a esquerda, estigma verde e estames com anteras amarelo-claro; no $2^{\circ}$ dia, as flores encontravam-se menos vistosas, uma vez que, as sépalas e pétalas apresentavam um amarelo mais claro, pistilo castanho-escuro, já devidamente posicionado em um dos lados da flor, estigma escurecido e estames com anteras castanho-escuro; no $3^{\circ}$ dia, as flores apresentavam-se esmaecidas, com pétalas mais susceptíveis à queda, pistilo vináceo e estames já ausentes; $\mathrm{e}$ no $4^{\circ}$ dia, restavam apenas o pistilo e o cálice, e por ventura, uma ou duas pétalas.

O estigma só esteve receptivo nas flores de $1^{\circ}$ e $2^{\circ}$ dia (Tab. 1). Estes resultados diferiram dos obtidos para outras 
Tabela 1. Receptividade estigmática das flores de Senna cana (Nees \& Mart.) H.S. Irwin \& Barneby

\begin{tabular}{lccc}
\hline Hora & Flor de $1^{\circ}$ dia & Flor de 2 ${ }^{\circ}$ dia & Botões em Antese \\
\hline $07: 00$ & $90 \%$ & $100 \%$ & 0 \\
$12: 00$ & $100 \%$ & $70 \%$ & 0 \\
$17: 00$ & $80 \%$ & $70 \%$ & 0 \\
\hline
\end{tabular}

espécies do gênero, nas quais a receptividade estigmática foi observada desde os botões em antese (Silva et al. 2002; Carvalho \& Oliveira 2003; Torres 2009). Os grãos de pólen de todos os tipos de anteras, com a exceção dos estaminódios, apresentaram alta viabilidade (100\%) desde os botões em final de antese até as flores de $2^{\circ}$ dia, do mesmo modo como observado por Carvalho \& Oliveira (2003) em S. sylvestris, e por Torres (2009) em S. multijuga.

Senna cana não apresentou osmóforos, tampouco pigmentos que refletem raios ultravioletas nas flores, diferentemente dos resultados obtidos por Torres (2009), para S. multijuga, quando foi observada a presença de osmóforos desde a base até o ápice das anteras.

Quanto ao sistema reprodutivo, após a polinização cruzada manual $(\mathrm{N}=20), 50 \%$ das flores formaram frutos, enquanto que para o grupo controle $(\mathrm{N}=40), 70 \%$ formaram frutos (Tab. 2). Entretanto, após os tratamentos de autopolinização espontânea e induzida, não foi observado o desenvolvimento de frutos (Tab. 2), o que possivelmente se deve a uma auto-incompatibilidade na espécie. Assim como observado em S. cana, a auto-incompatibilidade também já foi verificada em outras espécies do gênero: $S$. australis (Silva et al. 2002), S. sylvestris (Carvalho \& Oliveira 2003) e S. multijuga (Torres 2009).

Os resultados obtidos com os testes de polinização controlados permitem que sejam feitas inferências acerca do sistema reprodutivo da espécie. Além de que, justificam a importância da síndrome de melitofilia e estratégias fenológicas apresentadas pela espécie enquanto mecanismos que favorecem a atração de visitantes florais (incluindo polinizadores), pois em se tratando de uma espécie autoincompatível, ela depende de agentes externos para efetuar a transferência do pólen para o estigma, e, portanto, se utiliza de mecanismos de polinização cruzada para garantir seu sucesso reprodutivo.

\section{Visitantes florais}

Os visitantes florais observados foram insetos pertencentes a quatro ordens: Hymenoptera (abelhas, formigas e vespas), Lepidoptera (borboletas), Coleoptera (besouros) e Hemíptera, sendo Hymenoptera a ordem que teve o maior número de espécies e, dentre essas, predominaram abelhas pertencentes às famílias: Apidae e Halictidae.

O principal comportamento observado foi a coleta de pólen nas flores. Segundo Faegri \& van der Pijl (1979), as abelhas são os principais polinizadores das flores de angiospermas, uma vez que estão entre os grupos de animais melhor adaptados a essa atividade e, na maioria dos casos, dependem dos recursos florais oferecidos para a sua alimentação. O pólen, por sua vez, além de ser o condutor dos gametas masculinos, e sendo assim, elemento de extrema importância para o sucesso reprodutivo das plantas, trata-se de uma rica fonte protéica. Por este motivo, configura-se como um dos principais recursos nutritivos oferecidos aos polinizadores (Faegri \& van der Pijl 1979).

Espécies de Fabaceae, pertencentes à subfamília Caesalpinioideae, costumam estar relacionadas à síndrome de melitofilia por apresentarem, principalmente, flores com anteras poricidas e, portanto, o pólen como atrativo primário e recurso floral disponível (Faegri \& van der Pijl 1979; Gimenes et al. 2007). Como a espécie estudada não apresentou quaisquer outros recursos florais, como glândulas de odor e pigmentos que refletem raios ultravioletas, a atração aos visitantes florais se deu devido a presença de anteras poricida, somada ao amarelo intenso da corola, a presença de plataforma de pouso e a simetria zigomorfa, que configuram caracteres relacionados à síndrome de melitofilia, segundo Faegri \& van der Pijl (1979).

A atividade das abelhas nas flores de $S$. cana iniciou por volta das 6:00h, permanecendo intensa até as 10:00h, de modo que a tarde as visitas tornavam-se bastante escassas. Das espécies coletadas, apenas Xylocopa frontalis Olivier (1789) e Xylocopa grisescens Lepeletier (1841) (Apidae) foram classificadas como potenciais polinizadores (Tab. 3 ), pois apesar das breves visitas (com duração de até 2 segundos), visitaram um maior número de flores (Fig. 3), e foram as únicas espécies em que foi observado o contato do estigma da flor com o corpo do animal, o qual se encontrava coberto de pólen. Tais espécies, ao se aproximarem da flor, prendiam-se à base das anteras com o primeiro par de pernas, e a vibração promovida por seus músculos de vôo era transmitida às anteras, contribuindo assim, com a liberação dos grãos de pólen (Fig. 4A-C). Estes então eram transferidos com o auxílio das pernas anteriores e médias para as escopas, localizadas em suas pernas posteriores, do mesmo modo como foi observado por Torres (2009), para os polinizadores de Senna multijuga.

As espécies de Xylocopa visitaram diversas flores na mesma inflorescência, e várias inflorescências por indivíduo. Outros trabalhos também relatam a participação de abelhas pertencentes à tribo Xilocopini, como polinizadores de Fabaceae (Carvalho \& Oliveira 2003; Leite \& Machado 2009; Nogueira \& Arruda 2006; Torres 2009).

Flores com anteras poricidas favorecem as visitas realizadas por abelhas de grande porte, capazes de realizar a coleta do pólen através de um mecanismo denominado 
Tabela 2. Produção de frutos (porcentagem) de Senna cana (Nees \& Mart.) H.S. Irwin \& Barneby após tratamentos de polinização controlados na mata ciliar do rio Lençóis, município de Lençóis, Chapada Diamantina, Bahia.

\begin{tabular}{lcc}
\hline Tratamento & N $^{\circ}$ de Flores & \% Frutos \\
\hline Autopolinização Espontânea & 30 & 0 \\
Autopolinização Induzida & 10 & 0 \\
Polinização Cruzada Manual & 20 & 50 \\
Polinização Natural & 40 & 70 \\
\hline
\end{tabular}

"buzz pollination" ou polinização por vibração (Viana \& Kleinert 2006), resultando em uma polinização eficiente das flores (Oliveira-Rebouças \& Gimenes 2004), em vista de seu tamanho corporal que facilita o acesso ao estigma (Borges et al. 2002). De acordo com levantamento bibliográfico realizado por Nunes-Silva et al. (2010), este mecanismo de coleta pode ser encontrado em diferentes espécies de abelhas das famílias: Andrenidae, Apidae (com exceção das abelhas do gênero Apis), Colletidae, Halictidae e Megachilidae.

O mecanismo de coleta do pólen através da vibração dos músculos do vôo foi também realizado por oito outras espécies de abelhas visitantes de $S$. cana, além das espécies de Xylocopa, dentre elas: Centris sp., Centris sponsa Smith (1854), Eulaema cingulata Fabricius (1804), Bombus brevivilus Franklin (1913) e Bombus morio Swederus (1787), pertencentes à família Apidae; e Augochloropsis sp., Pseudaugochlora sp. e Pseudaugochlora graminea Fabricius (1804), pertencentes à família Halictidae. Entretanto, estas espécies foram classificadas como pilhadoras (Fig. 4D), em vista de não contatarem o estigma durante as visitas.

Abelhas de pequeno porte, como as espécies de Halictidae encontradas nas flores de S. cana, também realizam a coleta do pólen através do mecanismo de vibração das anteras (Carvalho et al. 2001; Viana \& Kleinert 2006). Porém, em função do seu

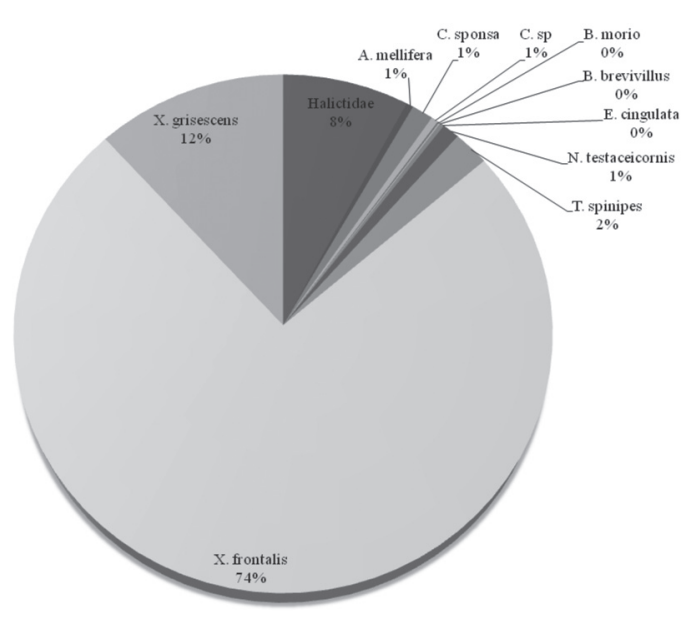

Figura 3. Percentual das flores de Senna cana (Nees \& Mart.) H.S. Irwin \& Barneby visitadas por espécies de abelhas (Hymenoptera: Apoidea) no município de Lençóis, Chapada Diamantina, Bahia.

tamanho, raramente contatam o estigma das flores durante as visitas, por isso são consideradas "furtadoras" (Viana \& Kleinert 2006), visitantes oportunistas, ou, no máximo, polinizadores casuais em flores com anteras poricidas (Oliveira-Rebouças \& Gimenes 2004). Entretanto, em vista das suas visitas diminuírem o suprimento de pólen para os reais polinizadores de $S$. cana, acabam contribuindo positivamente com a eficiência de seus polinizadores, uma vez que, estes são obrigados a visitar um número maior de flores a fim de assegurar um suprimento necessário de pólen (Viana \& Kleinert 2006).

Além das espécies de abelhas supracitadas, foram observadas ainda três outras espécies que não realizavam o mecanismo de vibração para a coleta dos grãos de pólen, tampouco foram vistas contatando o estigma floral: Apis mellifera scutellata Lepeletier (1836), Nannotrigona testaceicornis Lepeletier (1836) e Trigona spinipes Fabricius (1793).

Tabela 3. Espécies de abelhas (Hymenoptera: Apoidea) visitantes e sua função ecológica nas flores de Senna cana (Nees \& Mart.) H.S. Irwin \& Barneby, em espécimes presentes no município de Lençóis, Chapada Diamantina, Bahia. Legenda: Po = Potencial polinizador; $\mathrm{Pi}=\mathrm{Pilhador;} \mathrm{La}=\mathrm{Ladrão}$.

\begin{tabular}{llc}
\hline Família & Espécie & Função \\
\hline & Apis mellifera scutellata Lepeletier (1836) & $\mathrm{Pi}$ \\
& Bombus brevivilus Franklin (1913) & $\mathrm{Pi}$ \\
& Bombus morio Swederus (1787) & $\mathrm{Pi}$ \\
& Centris sp. & $\mathrm{Pi}$ \\
& Centris sponsa Smith (1854) & $\mathrm{Pi}$ \\
Apidae & Eulaema cingulata Fabricius (1804) & $\mathrm{Pi}$ \\
& Nannotrigona testaceicornis Lepeletier(1836) & $\mathrm{Pi}$ \\
& Trigona spinipes Fabricius (1793) & $\mathrm{La}$ \\
& Xylocopa frontalis Olivier (1789) & $\mathrm{Po}$ \\
Xylocopa grisescens Lepeletier (1841) & $\mathrm{Po}$ \\
\hline Halictidae & Augochloropsis sp. & $\mathrm{Pi}$ \\
& Pseudaugochlora sp. & $\mathrm{Pi}$ \\
& Pseudaugochlora graminea Fabricius(1804) & $\mathrm{Pi}$ \\
\hline
\end{tabular}



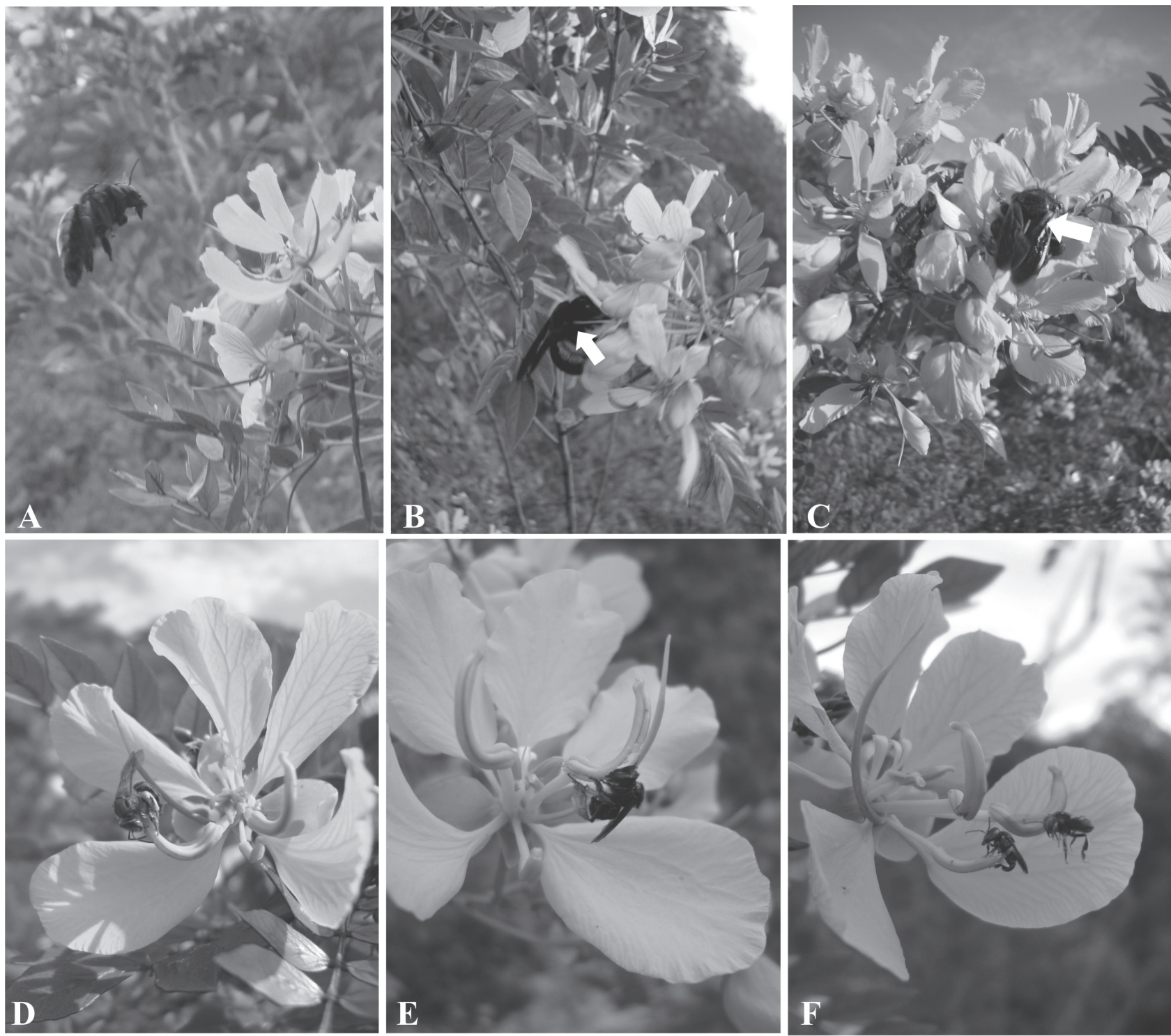

Figura 4. Abelhas visitantes das flores de Senna cana (Nees \& Mart.) H.S. Irwin \& Barneby em espécimes presentes no município de Lençóis, Chapada Diamantina Bahia. A - Aproximação de Xylocopa frontalis Olivier (1789) à flor; B - Estigma contatando X. frontalis em sua porção lateral; C - Estigma contatando a porção dorsal do tórax de X. frontalis; D - Espécie de Halictidae posicionado no ápice da antera promovendo vibração para a coleta de pólen; E - Trigona spinipes Fabricius (1793) mastigando a antera em busca de pólen; F - Nannotrigona testaceicornis Lepeletier (1836) posicionada no ápice da antera a procura de grãos de pólen.

A primeira (A. mellifera scutellata) foi vista apenas caminhando pelas anteras, aleatoriamente, em busca de grãos de pólen. Nannotrigona testaceicornis também apresentou um comportamento estritamente "vasculhatório", onde elas apenas caminhavam pelas anteras a procura de grãos de pólen que por ventura tivessem sido liberados através do mecanismo vibratório de coleta realizado por outras espécies de abelhas, ou mesmo eram vistas no ápice das anteras introduzindo sua língua no poro a fim de se alimentar dos grãos de pólen situados em sua porção mais superior (Fig. $4 \mathrm{~F})$. T. spinipes apresentou um comportamento predatório, como também descrito por outros autores (Borges et al. 2002; Silva et al. 2002; Carvalho \& Oliveira 2003; Viana \& Kleinert 2006), no qual além de posicionar-se a princípio no ápice das anteras, introduzindo sua língua no poro a fim de recolher os grãos de pólen mais superficiais (do mesmo modo como observado em $N$. testaceicornis), a espécie também utilizava suas mandíbulas denteadas e providas de forte musculatura para perfurar e cortar as anteras, a fim de ter acesso aos grãos de pólen presentes em seu interior (Fig. 4E). Viana \& Kleinert (2006) ressaltam que o comportamento predatório realizado por Trigona confere uma perda reprodutiva para a planta, uma vez que, as abelhas vibradoras de grande porte e potenciais polinizadoras, tendem a evitar as flores visitadas por essa espécie.

Sendo assim, $N$. testaceicornis e A. mellifera scutellata foram tidas como mais duas espécies pilhadoras das flores de $S$. cana, enquanto que T. spinipes foi classificada como "ladrão de pólen", de acordo com a terminologia proposta por Inouye (1980). 
De fato, a síndrome de melitofilia garantiu a S. cana a atração de muitos visitantes florais, incluindo seus polinizadores (Hymenoptera: Apoidea) - agentes de extrema importância para a sua reprodução, visto se tratar de uma espécie auto-incompatível. Entretanto, seu sucesso reprodutivo e consequente estabelecimento devem-se, não apenas aos caracteres morfo-estruturais das flores, como também às estratégias fenológicas foliares e reprodutivas, como: o padrão anual/sazonalidade, que faz da espécie uma fonte de recursos para várias abelhas nativas em um determinado período do ano (Kiill et al. 2010); a duração intermediária, que garante a disponibilidade de recursos florais por um bom intervalo de tempo; a alta sincronia intra-específica da floração, que confere à população em meio à paisagem, um display visual extremamente eficiente na atração de visitantes florais e polinizadores, ao passo que, a abundância de flores/pólen garante a constância das visitas, e, por conseguinte, a reprodução da espécie (Bezerra \& Machado 2003); e ainda a relação entre a alta sincronia nas fases de queda de folhas e frutos maduros favorecendo o processo de dispersão dos diásporos autocóricos durante o período seco. Os resultados deste estudo sugerem que tais estratégias podem ser atribuídas ao gênero Senna, tendo em vista que estudos anteriores envolvendo aspectos de fenologia e/ou biologia floral de outras espécies (Borges et al. 2002, Silva et al. 2002, Carvalho \& Oliveira 2003, Oberlaender 2006, Torres 2009) deram suporte a esta investigação.

\section{Agradecimentos}

As autoras agradecem a Luciano Paganucci de Queiroz pela identificação de Sena cana, Favízia Freitas de Oliveira pela identificação das abelhas, e Patrícia Luiza Rebouças e Miriam Gimenes pelos comentários valiosos aos aspectos de biologia floral e visitantes do manuscrito. Este projeto teve suporte da Fundação de Amparo à Pesquisa do Estado da Bahia (FAPESB 5303/2009) e Conselho Nacional de Desenvolvimento Científico e Tecnológico (CNPq 480508/2008). I.M.S. teve bolsa da FAPESB. L.S.F. tem bolsa (PQ2) do CNPq.

\section{Referências bibliográficas}

Augspurger, C.K. 1981. Reproductive synchrony of tropical plants: experimental effects of pollinators and seed predators on Hybanthus prunifolius (Violaceae). Ecology 62: 775-778.

Bencke, C.S.C. \& Morellato, L.P.C. 2002. Comparação de dois métodos de avaliação da fenologia de plantas, sua interpretação e representação. Revista Brasileira de Botânica 25(3): 269-276.

Bezerra, E.L.S \& Machado, I.S. 2003. Biologia floral e sistema de polinização de Solanum stramonifolium Jacq. (Solanaceae) em Remanescente de mata atlântica, Pernambuco. Acta Botanica Brasilica 17(2): 247-257.

Borges, M.S.; Viana, B.F. \& Neves, E.L. 2002. Aspectos da estratégia reprodutiva de duas espécies co-ocorrentes de Senna (K. Bauhin) P. Miller (Caesalpiniaceae) nas dunas do médio rio São Francisco, Bahia. Sitientibus Série Ciências Biológicas 2(1/2): 49-54.
Bulhão, C.F. \& Figueiredo, P.S. 2002. Fenologia de leguminosas arbóreas em uma área de cerrado marginal no nordeste do Maranhão. Revista Brasileira de Botânica 25(3): 361-369.

Carvalho, C.A.L.; Marques, O.M.; Vidal, C.A. \& Neves, A.M.S. 2001. Comportamento de forrageio de abelhas (Hymenoptera, Apoideae) em flores de Solanum palinacanthum Dunal (Solanaceae). Revista Brasileira de Zoociências 3: 35-44.

Carvalho, D.A. \& Oliveira, P.E. 2003. Biologia reprodutiva e polinização de Senna sylvestris (Vell.) H.S. Irwin \& Barneby (Fabaceae, Caesalpinioideae). Revista Brasileira de Botânica 26(3): 319-328.

Castro, M.S. 2001. A comunidade de abelhas (Hymenoptera: Apoidea) de uma área de caatinga arbórea entre os inselbergs de Milagres (1259'S; 3951'W), Bahia. Tese de Doutorado, Universidade de São Paulo, Brasil.

Cerqueira, C.O.; Funch, L.S. \& Borba, E.L. 2008. Fenologia de Syngonanthus mucugensis Giul. subsp. mucugensis e S. curralensis Moldenke (Eriocaulaceae), nos municípios de Mucugê e Morro do Chapéu, Chapada Diamantina, BA, Brasil. Acta Botanica Brasilica 22(4): 962-969.

Dafni, A. 1992. Pollination ecology: a practical approach (the practical approach series). New York, Oxford, University Press.

Dutra, J.C.S. \& Machado, V.L.L. 2001. Entomofauna Visitante de Stenolobium stans (Juss.) Seem (Bignoniaceae), Durante seu Período de Floração. Neotropical Entomology 30(1): 43-53.

Faegri, K. \& van der Pijl, L. 1979. The Principles of Pollination Ecology. Pp. 115-119. 3 ed. Oxford, Pergamon Press.

Fournier, L.A. 1974. Un método cuantitativo para La medición de características fenologicas en árboles. Turrialba 24: 422-423.

Frankie, G.W.; Baker, H.G. \& Opler, P.A. 1974. Comparative phenological studies of trees in tropical lowland wet and dry forest sites of Costa Rica. Journal of Ecology 62: 881-913.

Funch, L.S.; Funch, R. \& Barroso, G.M. 2002. Phenology of gallery and montane forest in the Chapada Diamantina, Bahia, Brazil. Biotropica 34(1): 40-50.

Gimenes, M. \& Lobão, C.S. 2006. A Polinização de Krameria bahiana BB Simpson (Krameriaceae) por Abelhas (Apidae) na Restinga, BA. Neotropical Entomology 35: 440-445.

Gimenes, M.; Oliveira-Reboucas, P.L. \& Almeida, G.F.de. 2007. Estudo das interações entre abelhas e flores em um ecossistema de restinga na Bahia. Sitientibus, Série Ciências Biológicas 7: 347-353.

Inouye, D.W. 1980. The terminology of floral larceny. Ecology 61(5): 1251-1253.

Kiill, L.H.P.; Martins, C.T. de V.D. \& Silva, P.P. 2010. Biologia reprodutiva de duas espécies de Anacardiaceae da caatinga ameaçadas de extinção. Pp. 337-364. In: Albuquerque, U.P.; Moura, E.L.; Araújo, E.L. (Org.). Biodiversidade, potencial econômico e processos eco-fisiológicos em ecossistemas nordestinos. Bauru, Canal6.

Lammi, J. 2005. Cálculo del fotoperiodo. Disponível em: <http://www. tutiempo.net/silvia_larocca/Temas/fotoperiodo.htm $>$. Acesso em: $16 / 06 / 2010$

Leite, A.V. \& Machado, I.C. 2009. Biologia reprodutiva da "catingueira" (Caesalpinia pyramidalis Tul., Fabaceae-Caesalpinioideae), uma espécie endêmica da Caatinga. Revista Brasileira de Botânica 32(1): 79-88.

Lenzi, M. \& Orth, A.I. 2004. Fenologia reprodutiva, morfologia e biologia floral de Schinus terebinthifolius Raddi (Anacardiaceae), em restinga da Ilha de Santa Catarina, Brasil. (UFSC), Florianópolis, Santa Catarina. Biotemas 17(2): 67-89.

Lenzi, M.; Orth, A.I. \& Guerra, T.M. 2005. Ecologia da polinização de Momordica charantia L. (Cucurbitaceae), em Florianópolis, SC, Brasil. Revista Brasileira de Botânica 28(3): 505-313.

Lewis, G.P. 2005b. Cassieae. Pp. 111-26. In: Lewis, G.P.; Schrire, B.; Mackinder, B. \& Lock, M. (Eds.). Legumes of the world. Kew, Royal Botanic Gardens.

Locatelli, E. \& Machado, I.C. 2004. Fenologia de espécies arbóreas de uma Mata Serrana (Brejos de Altitude) em Pernambuco, Brasil. Pp. 255-276. In: Pôrto, K.; Tabarelli, M.; Machado, I.C. (Orgs.). Brejos de Altitude: História Natural, Ecologia e Conservação. Brasília, MMA/PROBIO/CNPq. 
Machado, I.C. \& Lopes, A.V. 2004. Floral Traits and Pollination Systems in the Caatinga, a Brazilian

Tropical Dry Forest. Annals of Botany 94: 365-376.

Marques, A.R. \& Lemos Filho, J.P. 2008. Fenologia reprodutiva de espécies de bromélias na Serra da Piedade, MG, Brasil. Acta Botanica Brasilica 22: 417-424.

Martin-Gajardo, I.S. \& Morellato, L.P.C. 2003. Fenologia de espécies Rubiaceae do sub-bosque em floresta Atlântica no sudeste do Brasil. Revista Brasileira de Botânica 26(3): 299-309.

Newstrom, L.E.; Frankie, G.W. \& Baker, H.G. 1994. A New Classification for Plant Phenology Based on Flowering Patterns in Lowland Tropical Rain Forest Trees at La Selva, Costa Rica. Biotropica 26(2): 141-159.

Nogueira, E.M.L. \& Arruda, V.L.V. de. 2006. Fenologia reprodutiva, polinização e sistema reprodutivo de Sophora tomentosa L. (Fabaceae - Papilionoideae) em restinga da praia da Joaquina, Florianópolis, sul do Brasil. Biotemas 19(2): 29-36.

Nunes-Silva, P.; Hrncir, M. \& Imperatriz-Fonseca, V.L. 2010. A polinização por vibração. Oecologia Australis 14(1): 140-151.

Oberlaender, E.R. 2006. Fenologia de Senna macranthera (Collad.) Irwin \& Barneby e Senna multijuga (Rich.) Irwin \& Barneby no Parque Nacional da Serra dos Órgãos e na área urbana de Teresópolis RJ. Dissertação de Mestrado, Universidade Federal Rural do Rio de Janeiro, Instituto de Florestas, Rio de Janeiro.

Oliveira-Rebouças, P. \& Gimenes, M. 2004. Abelhas (Apoideae) visitantes de flores de Comolia ovalifolia DC Triana (Melastomataceae) em uma área de Restinga na Bahia. Neotropical Entomology 33(3): 315-320.

Pinheiro, M.T. \& Sazima, M. 2007. Visitantes Florais e Polinizadores de Seis Espécies Arbóreas de Fabaceae Melitófilas na Mata Atlântica no
Sudeste do Brasil. Porto Alegre. Revista Brasileira de Biociências 5(1): 447-449.

Queiroz, L.P. 2009. Leguminosas da Caatinga. Feira de Santana, Universidade Estadual de Feira de Santana.

Santos, D.L. \& Takaki, M. 2005. Fenologia de Cedrela fissilis Vellozo (Meliaceae) na região rural de Itirapina, São Paulo. Acta Botanica Brasilica 19(3): 625-632.

Siegel, S. 1975. Estatística não-paramétrica: para as ciências do comportamento. São Paulo, Ed. McGraw-Hill do Brasil.

Silva, A.L.G.; Pinheiro, M.C.B. \& Ormond, W.T. 2002. Biologia floral e reprodutiva de Senna australis (Vell.) Irwin \& Barneby (Fabaceae, Caesalpinioideae). Boletim do Museu Nacional, Nova Série Botânica, Rio de Janeiro, 121: 01-11.

Torres, M.W. 2009. Biologia reprodutiva e polinização de Senna multijuga no Parque Nacional de Itatiaia e na Área de Proteção Ambiental da Serrinha do Alambari. Dissertação de Mestrado, Instituto de Pesquisas Jardim Botânico do Rio de Janeiro/ Escola Nacional de Botânica Tropical, Rio de Janeiro.

Vásquez, S.P.F. \& Webber, A.C. 2010. Biologia floral e polinização de Casearia grandiflora, Casearia. javitensis e Lindackeria paludosa (Flacourtiaceae) na região de Manaus, AM. Revista Brasileira de Botânica 33(1): 131-141.

Viana, B.F.; F.O. Silva \& A.M.P. Kleinert. 2006. A Flora apícola de uma área restrita de dunas litorâneas, Abaeté, Salvador, Bahia. Revista Brasileira de Botânica 29: 13-25

Williams-Linera, G. \& Meave, J. 2002. Patrones Fenológicos. Pp. 407431. Manuel R. Guariquata \& Gustavo H. Kattan. In: Ecologia Y Conservacion De Bosques Neotropicales. Universidad Nacional Autonoma. Costa Rica, Libro Universitario Regional. 